\title{
USING OF WIKI-TECHNOLOGIES IN THE PROCESS OF LEARNING ENGLISH FOR STUDENTS OF NON-LANGUAGE SPECIALTIES
}

\author{
Yerlan Idrissov ${ }^{1}$, Madina Tussupbekova ${ }^{2}$ \\ ${ }^{1}$ L.N. Gumilyov Eurasian National University, Nur-Sultan, Kazakhstan \\ ${ }^{2}$ L.N. Gumilyov Eurasian National University, Nur-Sultan, Kazakhstan
}

ORCID ID: 0000-0002-1285-1959

\begin{abstract}
This article presents the theoretical analysis of using the wiki technology in the process of teaching English to non-linguistic students. The author studies the potential of wiki technology in developing reading, writing and speaking skills. Moreover, this paper demonstrates the positive aspects of wiki technology. As a result of the researching, it is noted that the wiki technology is one of the necessary and useful technologies in teaching and learning English in higher schools.
\end{abstract}

\section{INTRODUCTION}

In view of the political and economic internationalization, English became more and more important. Since Kazakhstan announced its independence, President Nursultan Nazarbayev has constantly been advocating a trilingual model: each citizen of Kazakhstan should strive to gain fluency in English, Russian, and Kazakh. Accordingly, the national project 'Trinity of languages' determines Kazakh as the state language, Russian as an official language, and English as the language of international communication [Nazarbayev, 2007]. Thus, learning English has become a reality and a requirement of modern society, in connection with this methodology of learning and teaching a foreign language are also subject to constant progress together with Internet technologies in the educational environment. The object of research is a wiki technology and its effectiveness in the perspective of teaching English to students of non-linguistic specialties.

In modern educational programs, considerable attention is paid to the goals and content of learning a foreign language. However, learning a foreign language requires serious efforts from students. For this reason, the need to introduce additional methods and techniques to increase students' interest in mastering a foreign language.

One of the effective tools for teaching in the last two years has been wiki technology [Arsova, 2021; Petrova, Aleksandrov, 2018].

. The relevance of the frequent use of this technology is due to the modernization of the education system and the forced distance learning in connection with the corona virus pandemic.

The word "wiki-wiki" is borrowed from the Hawaiian language and means "quickly". Fast and easy access to information and to a single wiki document makes it possible to work together at a distance, including an unlimited number of participants [Bean, Hott, 2005]. Participants working on a single wiki document have no limits on what they can do, and can post, add, and edit in real time. Thus, learning English on the basis of the proposed project through a wiki document transforms the process of language learning from an individual to a collective format. This technology may well be applicable to English language students because it provides interactivity and teacher-student cooperation in a single educational resource, which allows directing and controlling the learning process.

There are some positive aspects of wiki technology in learning:

1) it develops the intellectual and creative abilities

2) creates the linguistic environment in the classroom

3) develops the personal qualities like independence, discipline, responsibility

4) individualizes of the learning process 
5) forms the language competences and skills.

The use of wiki technology is noted in the studies of G. Kessler and Y. Markova which are of experimental character, in the experiment of G. Kessler the acting foreign language teachers acted, which predetermined the positive results, in our case the participants of the experiment are students of non-language specialties, which complicates the task in training and suggests the unknown result in research in the application of wiki technology [Kessler, 2009].

As a result of Y. Markova's experiment, there is an equal focus on the content, structure, and linguistic side of the work when writing business letters, reports, messages, reviews and short articles on professional and social topics. The works and results of these researchers are a valuable contribution to the continued research on the use of wiki technology in foreign language teaching [Undibayeva, 2019]. Based on the generalization of studies by P. V. Sysoev, M. N. Evstigneev, Y. Y. Markova, the following didactic properties and methodological functions of wiki technology have been determined: Publicity, nonlinearity, possibility to access the history of document creation, multimedia, hypertext structure.

The validity of learning through wiki technology is reinforced by the fact that students practice their reading, writing, and speaking skills. English becomes the primary, working language for learning tasks, so students are already using the language directly to achieve their learning goals. As a result of the review of generalizations, the wiki technology includes the properties necessary when teaching students in tandem with the application of basic pedagogical technologies. It is expected that first of all students will develop the skill of reading and perception of information, further on students will train their writing and speaking skills while performing tasks.

\section{USING MODERN TECHNOLOGIES IN TEACHING PROCESS}

The process of mastering a foreign language contains many aspects, as this process itself is complex, especially for students with basic knowledge. For this reason, work continues on developing effective teaching methods. Methodologists and teachers have many educational platforms at their disposal designed to involve students in the process of learning a language or subject.

The most common types of used in teaching and the possibilities of their use to increase the level of motivation in learning a foreign language. One of the simplest types is electronic textbooks, dictionaries and encyclopedias. One of the most known electronic encyclopedias is Wikipedia developed on the basis of wiki technology; it was presented at the beginning of 2000. This source allowed the society to have easy access to information and knowledge. The simplicity of the interface and design, the links that allow going further to the following pages to concretize the information and to obtain new information. The ease of use of this technology allows professionals of different professions to apply it in training and get the expected results when creating their own product [Parker, Chao, 2007].

The use of Internet technologies and their tools firstly implies competence and digital literacy of the teacher and students. When teaching English, teachers have at their disposal modern educational technologies that allow them to give the necessary knowledge qualitatively and methodically and apply it in practice. One of the important tasks of a teacher of a foreign language is creation of conditions for practical mastering of language of each student, therefore wiki technology can be one of key tools for motivation and occurrence of interest at students to a subject, progress, level of intellectual culture raises. Secondly, when teaching English through wiki technology, especially for non-linguistic students, it is important to develop an effective work algorithm that allows to easily cope with the tasks during the learning process.

When planning the training on the wiki platform, first of all, it is necessary to determine what modern learning technologies can be applied. Such technologies as collaborative learning technology aimed at the idea of mutual learning, the main idea of which is to create conditions for active joint activity of students. Wiki platform can be an ideal platform for solving common tasks and goals, while fostering collective responsibility for the solution of learning tasks.

The next one of the well-known technologies is the technology of project-based learning, which involves a productive way of collecting, studying and analyzing information. In this case, the 
project activity of students on a single product is observed and implemented. Students get an opportunity to realize them in creativity there is an activation of independent and collective activity, which implies the use of wiki technology as a unifying factor of work on the project.

Communicative learning technology is universal, because it forms communicative competence of students necessary in conditions of intercultural communication. It should be noted that the wiki platform makes it possible to simulate communication, comprehend, analyze and correct the material, thus collective work leads to the successful completion of the learning task. Collaboratively developed product becomes correct, true and meaningful for learning.

Distance learning technology, which has a tendency of continuous development due to the multimedia nature of education, also includes wiki technology. As students independently search for information on the Internet to solve their educational tasks, the wiki service is a universal treasure trove of useful material, it is important that students apply theoretical knowledge in practice, and this technology allows to do it easily and accessible in one document. Based on the above, it is important to determine the value and possibility of implementing a wiki project in practice with non-language students. This technology will allow to involve students more intensively in learning English, as well as to develop their writing and speech skills through collaborative project work in a wiki document.

The most common pedagogical application of a wiki today is the use of technology to develop writing skills. Wikis are an ideal tool for improving writing because they provide additional opportunities for students to reflect on, check, publish, and analyze the creative process at all stages of the process. The appeal of this technology also lies in the fact that it best facilitates, due to a number of didactic properties, the organization of students' autonomous work: "Using a wiki, the teacher can set the direction or initiate the discussion, but the technology works more effectively when students have conscious autonomy over the process. This absolutely does not mean that authoritative opinion cannot be present in a wiki, but it can undermine the effectiveness of the medium". B. Lamb also notes five major benefits of using wiki technology to develop writing skills [Lamb, 2004]:

- stimulates written expression of thoughts;

- provides a low-cost and effective tool for collaborative work;

- encourages greater attention to text - additional revision, editing, and referencing of previously completed work;

- emphasizes writing as a process rather than creating a final product;

- allows students to find a readership.

This social service can also be used in pedagogical practice for the presentation, expansion and annotation of educational materials; joint creation of virtual local history and environmental excursions by schoolchildren and students; group creation of creative works - tales, poems, essays, projects; joint creation of teacher, student and school encyclopedias; professional communication of teachers and teachers and improving their professional competence.

E. Tonkin distinguishes four types of educational wikis:

- individual wikis, on which the user saves and edits his or her thoughts;

- laboratory wikis where the user saves his or her current writings and also provides additional opportunities for reviewing and editing by classmates;

- wikis for group writing;

- group knowledge repositories [Tonkin, 2005].

The experience of Western researchers has been summarized most fully by P. Duffy and A. Bruns. In their opinion, wikis can be used in the educational process:

- when working on research projects to document the work done;

- for outlining one's thoughts about books and articles read, and for creating a jointly annotated bibliographic list by faculty members;

- for publishing course information (timetable, assignments, handouts), leaving space for students' comments and questions;

- as a platform for professional communication with the possibility of corrections and additions by colleagues; 
- as a platform for brainstorming concepts with hyperlinks to other resources;

- as a presentation tool instead of traditional software, with students being able to insert their own comments and update content into the presentation;

- as a collaborative text creation tool [Duffy P., Bruns A., 2006].

\section{RESULTS}

Scholars reported about implication and applying wiki platform in educational process to learn main competencies as reading and writing. $(n=6)$ The major tasks which are applied during study experiments were the writing of business letters, reports, article reviews, essays, publications and stories. $(n=5)$ It is important to note that wiki technology provided interactions among participants for team skill training as well as social implications. It was reported also that integration of wiki technology and peer feedback progresses through a cycle of writing, peer feedback and rewriting. This process gives social meaning to writing and takes the form of a social activity with a real audience in mind rather than merely being an assignment given by teachers. $(n=3)$

Scholars claimed that wiki extends the blended learning course in English for Academic Purposes. The wiki platform is based on the wiki hosting service Wiki spaces because of its deductible and user-friendly interface that requires only minimum internet skills and can be used after a basic instructional session. The structure of the wiki space allows for a work-in-progress approach to differentiated learning. ( $n=6)$ Researchers have found that wiki technology can be successfully applied in the process of teaching a foreign language by developing students' ability to work individually and in a group. By involving all students at once, wiki technology fosters a culture of communication and responsibility for results. Besides the improvement of reading and writing skills the researchers noticed the students' increased computer literacy and willingness to do their work or projects well. $(\mathrm{n}=7)$

Modern educational technologies in the process of foreign language teaching are not indicated in the works and articles of the researchers, most of all they revealed possible types of activities in the lesson which can be used on the wiki platform.

As there is little data in the studies on the methodology of teaching English and possible tools for their successful application on the wiki platform, the problematic question of how to teach the language and what challenges may arise in the process of teaching non-language students remains. $(\mathrm{n}=1)$

The advantages of wiki technology in building teamwork, in developing writing and speaking skills are described in 8 research papers and only in 2 papers it is written how this technology helps to beginners and elementary level students to command English. $(n=8)$

Regarding disadvantages, researchers referred to a certain percentage of experimental students who reported feeling uncomfortable and unused to using a wiki platform for learning comparing it with a standard format. $(n=2)$ In other 8 research papers disadvantages were not classified.

\section{DISCUSSION}

The researched literature was taken as a basis for researching the topic of using wiki technology in English language teaching and in the educational process in particular. Most of the wiki technology is used as a platform for collaborative learning activities, which has been proven by numerous experiments with university and college students. The research clearly describes the didactic properties and methodological functions of wiki technology in foreign language teaching, which fully justifies the possibility of using this technology. It is noteworthy that this topic has been previously researched by foreign and Russian scholars, but the achievements in the field of wiki technology application for the development of writing and speech skills in foreign language teaching methodology, especially in the field of teaching written speech to non-language university students, need to be further developed. 
The existing contradiction between the requirements of educational standards to use interactive teaching methods to train students with proficiency in a foreign language at an advanced threshold and a small number of class hours has led to the need to develop a wiki-based model for teaching written and oral activity to non-linguistic university students to organize extracurricular independent work of students within a mixed learning mode. Research on this topic is ongoing, and many aspects of wiki technology application in education are being studied. Each researcher dealing with the topic has offered their own vision and come up with their personal result in the course of experimental application of wiki technology in teaching English. The developed theoretical base is very important for its successful practice; the algorithm of the development of students' writing skills including the preparatory, procedural and final stages with clear instructions sheds light on the further research and experimentation, as every research in this field has a different ending result.

In conclusion, the peculiarity of wiki technology integration in the process of foreign language teaching consists in expanding the ways of interaction between the participants of teaching, types of control the level formation of foreign language communicative competence in general and types of evaluation and the formation of written and speech skills, including the possibility of formative evaluation, self and mutual evaluation. The successful implementation of wiki-technology requires overcoming possible difficulties of technical, methodological, psycho-pedagogical and organizational nature.

The main contribution of the reviewed studies, that this information would be useful for English teachers searching innovative methods in teaching progress.

Because of changing needs in teaching methodology, wiki technology would be a one of the key solutions how to organize educational process successfully without losing students' immersion and interest in learning process. The tendency of digitalization of education forces to organize learning process through technologies which have distinct advantages rather than standard format of teaching, therefore wiki technology has all opportunities to substitute usual obsolete technologies.

\section{CONCLUSION}

The prospect of using wiki technologies in the process of teaching a foreign language tends to develop and apply in the lessons as a practical exercise. Correctly, the developed algorithm of work with students will allow carrying out a lesson qualitatively and productively. Classes through wiki technology emphasize practice and involvement in pair and group work, the limitless possibility of hypertext makes this technology flexible, easy and convenient to use. A wiki implements a radical model of collaborative hypertext, where the ability to create and edit any entry is given to each member of the online community. This distinction makes the wiki the most promising medium for collective hypertext writing, a modern "electronic whiteboard" on which an entire group can write.

Thus, with this technology, the user can:

- edit pages of the site/text directly in a web browser;

- keep hyperlinks between pages of the site/text up to date;

- use simplified markup for text instead of HTML;

- store all changes that have occurred to wiki articles since they were created.

Although wiki technology was developed more than a dozen years ago, it still has not taken its proper place in educational practice, either as a research method or as a teaching method. However, the popularity of the wiki has attracted the attention of enthusiastic teachers who see in this technology an opportunity not only to facilitate communication, but also to facilitate the process of searching, structuring, and sharing knowledge.

Wiki allows mastering a very special culture of writing non-linear electronic documents, which is currently very underdeveloped. This concept promotes cooperative learning (also referred to as cooperative learning, project-based learning, and problem-based learning), encourages communication and group work, facilitates the exchange of knowledge and experience, and promotes a spirit of cooperation rather than competition, because the radical model of collective hypertext based on this technology allows everyone in the online community to create and edit any entry. Wiki creates 
a special space that teaches students how to work as a group, how to create virtual communities, how to operate in a world where the accumulation of knowledge and information is increasingly a collective endeavor.

\section{REFERENCES}

Arsova, D. (2021). Skills and competencies of the new generation of students to work with digital devices // "Innovations in technology and education": proceedings of XIV International scientific conference "Innovations in technology and education", 26 march 2021 г.: Kuzbass State Technical University, Belovo, Russia; 2021. - vol. 3., pp. 59-66

Bean, L., \& Hott, D. D. (2005). Wiki: A speedy new tool to manage projects. Journal of Corporate Accounting \& Finance, 16(5), 3-8.

Duffy, P., \&Bruns, A. (2006). The use of blogs, wikis and RSS in education: A conversation of possibilities. In Learning on the Move: Proceedings of the Online Learning and Teaching Conference 2006 (pp. 31-38). Queensland University of Technology.

Kessler, G. (2009). Student-initiated attention to form in wiki-based collaborative writing. Language Learning \& Technology, 13(1), 79-95.

Lamb, B. (2004). Wide open spaces: Wikis ready or not. EDUCAUSE review, 39(5).

Nazarbayev, N. A. (2007). New Kazakhstan in the new world. Kazakhstanskaya pravda, (33), 25278.

Parker, K., \& Chao, J. (2007). Wiki as a teaching tool. Interdisciplinary Journal of e-learning and Learning Objects, 3(1), 57-72.

Petrova, M., Aleksandrov, M. Automating the virtual hosts maintenance in a multi-site environment. International Congress on Business and Marketing (ICBM'18), Marmara Eğitim Köyü Maltepe / İstanbul, TÜRKIYYE, Proceedings of the International Congress on Business and Marketing, 2018 Maltepe University, Istanbul, 29.11.2018-01.12.2018, ISBN 978-605-2124-0903, p.392-404

Tonkin, E. (2005). Making the case for a wiki. Ariadne, (42).

Undibayeva, M. K. (2019). Methods of using one of the component web 2.0-wiki technology in teaching foreign language. Znanie, (2-1), 53-65. 